\title{
Phenolic Compounds From Brewer's Spent Grains: Toward Green Recovery Methods and Applications in the Cosmetic Industry
}

\author{
Rodrigo Macias-Garbett, Sergio Othón Serna-Hernández, \\ Juan Eduardo Sosa-Hernández* and Roberto Parra-Saldívar* \\ School of Engineering and Sciences, Tecnologico de Monterrey, Monterrey, Mexico
}

\section{OPEN ACCESS}

Edited by:

Guadalupe Virginia Nevárez-Moorillón, Autonomous University of

Chihuahua, Mexico

Reviewed by:

Silvina Drago,

National University of

Littoral, Argentina

Bernardo Dias Ribeiro,

Federal University of Rio de

Janeiro, Brazi

Francisca Rodrigues,

LAQV Network of Chemistry and

Technology, Portugal

${ }^{*}$ Correspondence:

Juan Eduardo Sosa-Hernández eduardo.sosa@tec.mx Roberto Parra-Saldivar r.parra@tec.mx

Specialty section: This article was submitted to

Sustainable Food Processing, a section of the journal

Frontiers in Sustainable Food Systems

Received: 17 March 2021 Accepted: 18 May 2021

Published: 14 June 2021

Citation:

Macias-Garbett $R$, Serna-Hernández SO,

Sosa-Hernández JE and Parra-Saldivar R (2021) Phenolic Compounds From Brewer's Spent Grains: Toward Green Recovery Methods and Applications in the

Cosmetic Industry.

Front. Sustain. Food Syst. 5:681684. doi: 10.3389/fsufs.2021.681684
Brewers' spent grain (BSG) is the main by-product derived from the brewing industry, where it accounts for $85 \%$ of the total waste generated. The total annual production worldwide of this waste is 39 million tons. This lignocellulosic material is traditionally used as cattle feed and sold at a low retail price ( USD 45.00 per ton). However, efforts for the revalorization of this by-product are emerging since research has established that it can be used as a low-cost source of bioactive molecules and commodity chemicals that can bring value to integral biorefinery ventures. Among commodities, phenolic compounds have attracted attention as added-value products due to their antioxidant properties with applications in the food, cosmetic, and pharmaceutical industries. These phytochemicals have been associated with antiaging and anticancer activities that have potential applications on cosmetic products. This mini-review summarizes the most relevant extraction techniques used for the recovery of phenolic compounds from BSG while discussing their advantages and shortcomings and the potential applications from BSG bioactive extracts in the cosmetic industry and their reported beneficial effects. This mini-review also makes a brief comment on the role of phenolic compounds extraction in the economic feasibility of an integral BSG biorefinery.

Keywords: biorefinery and agro-industrial byproducts, brewer's spent grain, revalorization of industrial waste, cosmetic compounds, brewery byproducts

\section{INTRODUCTION}

Beer manufacturing involves many processes and different ingredients; therefore, many waste or by-products are generated. Brewers' spent grain (BSG) is the most abundant of such waste streams; $\sim 85 \%$ of all waste consists of this product (Aliyu and Bala, 2011). BSG is the remainder of the mashing process, the leftover malt or barley grain, alongside insoluble components left after the wort is filtered out. BSG usually is reserved and sold as cattle feed because it is rich in fiber and protein (see Table 1); however, it is highly abundant and therefore sold cheaply. It is estimated that about 39 million tons of BSG are produced annually worldwide and sold for animal feed at USD 45.00 per ton (Lynch et al., 2016). In recent years, BSG has been studied by different fields to maximize its usage and for the generation of added-value products, specifically in the biotechnological, pharmaceutical, and food industries, because of its unique characteristics and composition (Aliyu and Bala, 2011). 
TABLE 1 | Approximate composition of BSG.

\begin{tabular}{lc}
\hline \multicolumn{1}{c}{ BSG approximate composition } \\
\hline Component & Quantity $\mathbf{~ / 1 0 0 ~ g ~}$ \\
\hline Hemicellulose & 25 \\
Cellulose & 22 \\
Protein & 23 \\
Lignin & 18 \\
Lipids & 10 \\
Ashes & 2 \\
Phenolic compounds & $0.7-2.0$ \\
\hline
\end{tabular}

Adapted from Lynch et al. (2016) and Bonifácio-Lopes et al. (2019).

Additionally, consumers have been increasingly demanding natural ingredients as the formulation source for these industries. Thus, the cosmetic industry is looking for alternatives to synthetic or non-sustainable ingredients (Almendinger et al., 2020). BSG is a good source of valuable bioactive ingredients such as phenolic compounds extracted for the potential revalorization of this waste. The commercial usage of BSG bioactive extracts has already been explored as a nutraceutical ingredient, but its implementation in the cosmetic industry has only recently started to be proposed (Almendinger et al., 2020; Bucci et al., 2020; Di Domenico et al., 2020).

Phenolic compounds are antioxidants associated with reducing the risk of chronic diseases, cancer, and promoting health by protecting and preventing intracellular oxidative stress (Ikram et al., 2020). The phenolic compounds more abundantly found in BSG are hydroxycinnamic acids, specifically ferulic acid (FA) and p-coumaric acid (p-CA); sinapic, caffeic, and syringic acids to a lesser degree (Ikram et al., 2020). The specific content of each of these phenolic compounds can vary depending on the type of malt or barley grain used and the process it was subjected to Birsan et al. (2019) and Petrón et al. (2021). The extraction and utilization of these bioactive compounds have been studied and more recently associated with the cosmetic industry as possible ingredients to be used in skin care product formulations (Fukagawa et al., 2017; Almendinger et al., 2020; Leal et al., 2020). These phytochemicals are covalently linked to lignin by ether and ester bonds, which need to be considered when designing and choosing a good extraction technique (Ideia et al., 2020).

\section{PHENOLIC EXTRACTION METHODS APPLIED FOR BSG}

The recovery of phenolic compounds from BSG can be summarized in the following steps: pre-treatment, extraction, isolation, and purification (Routray and Orsat, 2012) (Figure 1). The first two steps can be regarded as especially important as they determine the overall yield of the process (Guido and Moreira, 2017). The pre-treatment of BSG grains helps break down the lignocellulosic material and improves the efficacy of the extractive process by facilitating solvent access to vacuoles and other storage structures (Bonifácio-Lopes et al., 2019).
Pre-treatment steps may include mechanical procedures like maceration, grinding, and homogenization of the material until a desirable particle size enhances the accessibility of solvents to cell wall structures (Niemi et al., 2012). Chemical pre-treatments like autohydrolysis (Pinheiro et al., 2019), alkaline hydrolysis (Ideia et al., 2020), and enzymatic pre-treatments (Mussatto et al., 2008) have been coupled to the extraction of phenolic and other bioactive compounds from BSG to enhance recovery yields. The use of pulsed electric fields, an emergent, and non-thermal pre-treatment, has also been proposed as a green, solvent-free extractive solution (Bouras et al., 2016; Kumari et al., 2019).

Along with phenolic compounds, the BSG extracts' antioxidant activity has been attributed to a synergic action of melanoidin compounds produced in the malting Maillard reaction, heightening the interest for their co-extraction. In the specific topic of the application of green recovery methods on BSG, coupled melanoidin extraction has been documented by Patrignani and González-Forte (2021), where the application of a microwave treatment was attributed as a promoter of Maillard reaction-derived products and the enhanced antioxidant activity of microwave-treated extracts was associated to a coupling of phenolic acid and melanoidin effects. On another reported green pre-treatment, Kumari et al. (2019) applied a pulsed electric field technology on light and dark BSG to enhance the extraction of bioactive compounds. Higher molecular weight compounds on dark BSG extracts were attributed to a higher melanoidin concentration. A higher antioxidant activity of dark BSG extracts compared to light BSG extracts was reported as well. A comprehensive list of technologies, methodologies and yields is presented in Table 2.

Researchers have used several extraction techniques to recover the phenolic compounds present in BSG (Figure 2). Solid/liquidbased extractions are the most common methods used, along with Soxhlet extraction, due to their low cost and ease of operation (Bonifácio-Lopes et al., 2019). More recently, the use of novel procedures has been proposed as an alternative to traditional approaches and considered "green techniques" due to their compliance with international regulation agencies' requirements (Ameer et al., 2017; Guido and Moreira, 2017). These green techniques offer comparable or higher yields of extraction and sustainable operation conditions (Vernès et al., 2020). Examples of this approach include supercritical fluid extraction (SFE), microwave-assisted extraction (MAE), and ultrasound-assisted extraction (UAE) and have been applied to different complicated substrates, i.e., microalgae (SosaHernández et al., 2018).

The industrial-scale implementation of green extraction methods for polyphenol recovery in agro-waste is dependent on the energetic and reagent consumption optimization of the process to make it comparable and competitive with currently available processes. Ameer et al. (2017) propose a 3-tier strategy for the modification of existing recovery strategies through (i) innovative and optimization-compliant strategies, (ii) usage of undedicated equipment, and (iii) the assessment of alternatives to traditional solvents. Similar propositions have already realized the large scale implementation of green polyphenol extraction in wastes with revalorization potential, such as the work done 


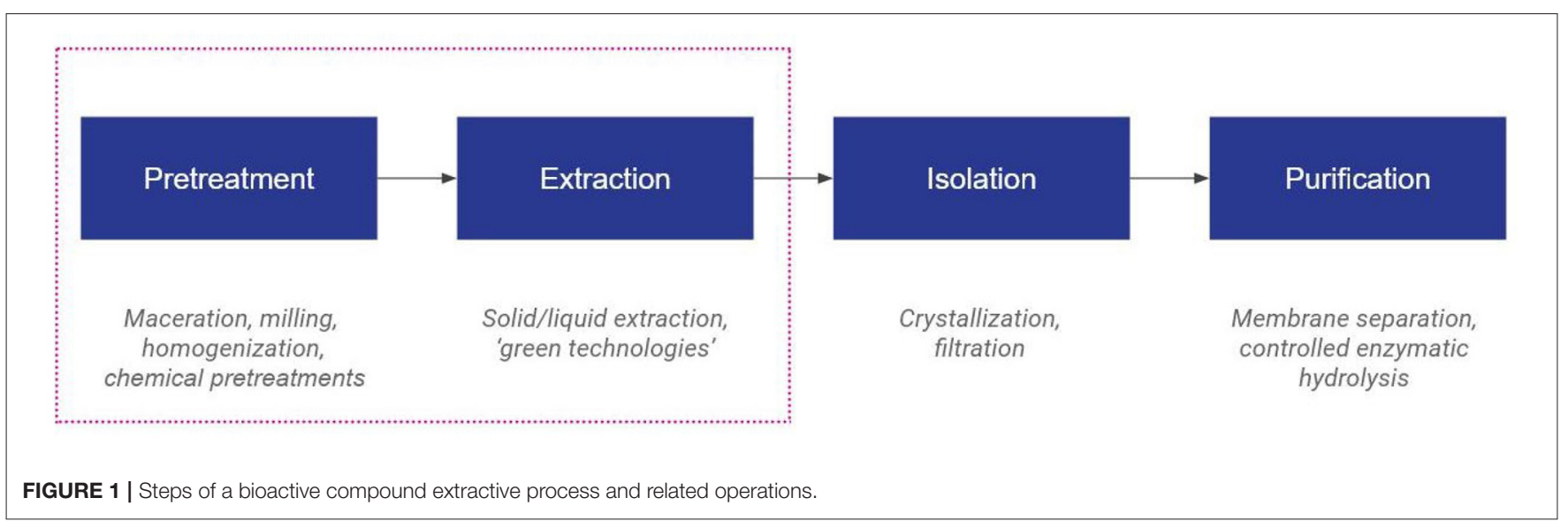

by Fia et al. (2020) that reports the industrial-scale $(1,080 \mathrm{~kg})$ treatment of unripe grape for the green recovery of bioactive compounds based on maceration, low temperatures, and solventfree recovery with potential implementation in the wine sector.

\section{Solid/Liquid Extraction}

Solid/liquid extraction (SLE) is the most common procedure for extracting phenolic compounds from BSG due to its simplicity and effectiveness (Vellingiri et al., 2014). The solvent composition, temperature, and time of extraction determine the technique's efficiency (Bonifácio-Lopes et al., 2019). Several solvents such as methanol, ethanol, water, acetone, and mixtures can be used (Meneses et al., 2013). Following the first extractive step, further separation and fractionations by liquid-liquid extraction and chromatography purify the extract (Guido and Moreira, 2017).

Alkaline hydrolysis is frequently coupled with SLE to improve extractive efficiency by degrading lignin and hemicelluloses and releasing not-bonded FA and p-CA (Wilkinson et al., 2014). A study by Hernanz et al. using this approach reported levels five times larger of extracted p-CA and FA, obtaining extracts with a yield of $0.1948 \pm 0.0143 \mu \mathrm{g} / \mathrm{g}$ for FA and $0.0794 \pm$ $0.0058 \mu \mathrm{g} / \mathrm{g}$ for $\mathrm{p}-\mathrm{CA}$, analyzed on 11 different varieties of ovendried and finely milled barley used for malting and feed purposes, in both pure malt (100\%) and malt/corn (80/20\%) compositions (Hernanz et al., 2001). The main drawback for SLE is the high volume of solvents required and long extraction times, as long as $16 \mathrm{~h}$ (Santos et al., 2003).

\section{Soxhlet Extraction}

The Soxhlet method offers time improvements over the conventional LSE of BSG phenolic compounds and is a wellestablished technique with high reproducibility (Guido and Moreira, 2017). Solvents such as methanol, ethanol, n-hexane, and ethyl acetate have been applied to extract phenolics from lignocellulosic materials (Stalikas, 2007). However, phenolic acids with high polarities, such as benzoic acid and cinnamic acid, can be lost with organic solvents, and a mixture with water may be necessary (Meneses et al., 2013). There are also concerns over the sustainability of the technique over the solvents used (Wang and
Weller, 2006). Thermolabile compounds can also be lost due to the temperature operations of the technique (Guido and Moreira, 2017).

A phenolic Soxhlet extraction (SE) from BSG was achieved by Moreira et al. in a timespan of $4 \mathrm{~h}$ using ethanol as the extracting solvent (Moreira et al., 2012). Nevertheless, the reported yield $(0.0014 \pm 0.0001 \%$ for FA, w/w), together with the process's disadvantages, may discourage BSG Soxhlet extraction in favor of better techniques. Further experimentation with optimized process conditions may improve yields and pose SE as a viable extractive procedure.

\section{Supercritical Fluid Extraction}

The speed, selectivity, and lack of residual solvents of supercritical fluid extraction (SFE) have posed it as an attractive alternative for the recovery of phenolic compounds, although its application on BSG has been limited (Bonifácio-Lopes et al., 2019). Carbon dioxide provides good solvation power, is cheap, environmentally friendly, and is regarded as safe by the FDA and EFSA (Herrero et al., 2010). In this method, the extraction time, pressure, temperature, and co-solvent presence are all determinants of the final yield, so process conditions are optimized based on the desired extract composition (Kitryte et al., 2015).

For the case of polyphenols, a mildly polar solvent (usually ethanol) is required as some studies have effectively reported zero yields when using only carbon dioxide (Guido and Moreira, 2017). The extraction of polyphenols from BSG using SFE has been reported (Kitryte et al., 2015; Spinelli et al., 2016). In the study by Spinelli et al. (2016), the extraction using $\mathrm{CO}_{2}$ plus $60 \%$ ethanol (v/v), $35 \mathrm{MPa}, 40^{\circ} \mathrm{C}$ and an extraction time of $240 \mathrm{~min}$, reported the highest recovery of phenolic molecules $(0.035 \pm$ $0.001 \%$ of total phenolic compounds, w/w). While effective, the use of SFE is restricted due to its high cost and specialized operating conditions (Guido and Moreira, 2017).

\section{Microwave-Assisted Extraction}

Microwave-assisted extraction (MAE) is an emergent technology that has also been applied for the extraction of polyphenols. Compared to previously discussed methods, the total extraction 
TABLE 2 | Average quantity of each phenolic compound from different extraction techniques.

\begin{tabular}{|c|c|c|c|c|c|c|c|c|c|}
\hline Extraction process & Ferulic ac. & $\begin{array}{l}\text { p-Coumaric } \\
\text { ac. }\end{array}$ & Synaptic ac. & Caffeic ac. & Syringic ac. & Total phenolics & Solvent & $\begin{array}{l}\text { Extraction } \\
\text { condition }\end{array}$ & References \\
\hline $\begin{array}{l}\text { Ultrasound assisted } \\
\text { extraction }\end{array}$ & $\begin{array}{l}22 \text { mAU (Area } \\
\text { under the curve) }\end{array}$ & $45 \mathrm{mAU}$ & $20 \mathrm{mAU}$ & - & - & $\begin{array}{l}114.23 \mathrm{mg} \\
\mathrm{GAE} / 100 \mathrm{~g} \mathrm{BSG}\end{array}$ & Acetone/Water (60/40\%, v/v) & $30 \mathrm{~min}, 60^{\circ} \mathrm{C}$ & Socaci et al., 2018 \\
\hline $\begin{array}{l}\text { Ultrasound assisted } \\
\text { extraction }\end{array}$ & $739.1 \mu \mathrm{g} / \mathrm{g} \mathrm{BSP}$ & $\begin{array}{l}3371.9 \mu \mathrm{g} / \mathrm{g} \\
\mathrm{BSG}\end{array}$ & $\begin{array}{l}11.11 \mathrm{ug} / \mathrm{g} \\
\mathrm{BSG}\end{array}$ & - & - & $1126.3 \mathrm{ug} / \mathrm{g}$ BSG & $\begin{array}{l}\text { Sodium hydroxide/Water } \\
(0.75 / 99.25 \%)\end{array}$ & $\begin{array}{l}35 \mathrm{kHz}, 30 \mathrm{~min}, \\
80^{\circ} \mathrm{C}\end{array}$ & Birsan et al., 2019 \\
\hline $\begin{array}{l}\text { Microwave assisted } \\
\text { extraction }\end{array}$ & - & $\begin{array}{l}112 \mu \mathrm{g} / \mathrm{g} \\
\mathrm{NSG}\end{array}$ & - & $142 \mathrm{ug} / \mathrm{g}$ & - & & & $2 \min , 150^{\circ} \mathrm{C}$ & \\
\hline $\begin{array}{l}\text { Microwave assisted } \\
\text { extraction }\end{array}$ & $\begin{array}{l}0.63 \mathrm{mg} \mathrm{GA} / \mathrm{g} \\
\mathrm{BSG}\end{array}$ & $\begin{array}{l}0.78 \mathrm{mg} \mathrm{GA} / \mathrm{g} \\
\mathrm{BSG}\end{array}$ & - & - & $\begin{array}{l}0.23 \mathrm{mg} \mathrm{GA} / \mathrm{g} \\
\mathrm{BSG}\end{array}$ & $\begin{array}{l}2.89 \mathrm{mg} \text { GA/g } \\
\mathrm{BSG}\end{array}$ & Choline chloride:glycerol & $13.3 \mathrm{~min}, 100^{\circ} \mathrm{C}$ & $\begin{array}{l}\text { López-Linares } \\
\text { et al., } 2021\end{array}$ \\
\hline $\begin{array}{l}\text { Microwave assisted } \\
\text { extraction }\end{array}$ & $1.31 \mathrm{~g} / 100 \mathrm{~g} \mathrm{BSG}$ & - & - & - & - & - & Sodium hydroxide $0.75 \%$ & $15 \mathrm{~min}, 100^{\circ} \mathrm{C}$ & $\begin{array}{l}\text { Moreira et al., } \\
2012\end{array}$ \\
\hline Solid/Liquid extraction & $\begin{array}{l}46.17 \mathrm{mg} / 100 \mathrm{~g} \text { of } \\
\text { BSG }\end{array}$ & - & - & - & - & $\begin{array}{l}118.5 \mathrm{mg} \\
\mathrm{GAE} / 100 \mathrm{~g} B S G\end{array}$ & $\begin{array}{l}\text { Sulfuric acid and sodium } \\
\text { hydroxide }\end{array}$ & $17,90 \mathrm{~min}, 120^{\circ} \mathrm{C}$ & $\begin{array}{l}\text { Sibhatu et al., } \\
2021\end{array}$ \\
\hline Solid/Liquid extraction & $145.3 \mathrm{mg} / \mathrm{L}$ & $138.8 \mathrm{mg} / \mathrm{L}$ & - & - & - & $284.1 \mathrm{mg} / \mathrm{L}$ & Sodium hydroxide & $90 \mathrm{~min}, 120^{\circ} \mathrm{C}$ & $\begin{array}{l}\text { Bonifácio-Lopes } \\
\text { et al., } 2019\end{array}$ \\
\hline Solid/Liquid extraction & - & - & - & - & - & $\begin{array}{l}3.57 \mathrm{mg} \mathrm{GAE} / \mathrm{g} \\
\mathrm{BSG}\end{array}$ & Ethanol/Water $(60 / 40 \%, v / v)$ & $60 \mathrm{~min}, 80^{\circ} \mathrm{C}$ & $\begin{array}{l}\text { Carciochi et al., } \\
2018\end{array}$ \\
\hline Solid/Liquid extraction & - & - & - & - & - & $4.26 \mathrm{mg} / \mathrm{GAE} \mathrm{g}$ & Acetone/water $(60 / 40 \%, v / v)$ & $60 \mathrm{~min}, 60^{\circ} \mathrm{C}$ & Zuorro et al., 2019 \\
\hline Solid/Liquid extraction & - & - & - & - & - & $\begin{array}{l}6.46 \mathrm{mg} \mathrm{GAE} / \mathrm{g} \\
\mathrm{BSG}\end{array}$ & Methano//Water $(80 / 20 \%, v / v)$ & $30 \mathrm{~min}, 60^{\circ} \mathrm{C}$ & $\begin{array}{l}\text { Meneses et al., } \\
2013\end{array}$ \\
\hline Solid/Liquid extraction & - & - & - & - & - & $\begin{array}{l}7.13 \mathrm{mg} \mathrm{GAE} / \mathrm{g} \\
\mathrm{BSG}\end{array}$ & Ethanol/Water $(60 / 40 \%, v / v)$ & $30 \mathrm{~min}, 60^{\circ} \mathrm{C}$ & $\begin{array}{l}\text { Meneses et al., } \\
2013\end{array}$ \\
\hline Solid/Liquid extraction & - & - & - & - & - & $\begin{array}{l}9.90 \mathrm{mg} \text { GAE } / \mathrm{g} \\
\mathrm{BSG}\end{array}$ & Acetone/Water (60/40\%, v/v) & $30 \mathrm{~min}, 60^{\circ} \mathrm{C}$ & $\begin{array}{l}\text { Meneses et al., } \\
2013\end{array}$ \\
\hline Solid/Liquid extraction & - & - & - & - & 122.2 mg/Kg & $\begin{array}{l}3,800 \mathrm{mg} \\
\mathrm{GAE} / \mathrm{Kg} \mathrm{BSG}\end{array}$ & Ethanol/water $(20 / 80 \%, v / v)$ & $24 \mathrm{~h}, 25^{\circ} \mathrm{C}$ & $\begin{array}{l}\text { da Rosa Almeida } \\
\text { et al., } 2017\end{array}$ \\
\hline $\begin{array}{l}\text { Supercritical carbon } \\
\text { dioxide extraction }\end{array}$ & - & - & - & - & - & $0.35 \mathrm{mg} / \mathrm{g} \mathrm{BSG}$ & CO2 and ethanol $60 \%(v / v)$ & $\begin{array}{l}240 \min , 40^{\circ} \mathrm{C}, 35 \\
\mathrm{MPa}\end{array}$ & Spinelli et al., 2016 \\
\hline Alkaline hydrolysis & $\begin{array}{l}476.99 \pm 25.94 \\
\mathrm{mg} / 100 \mathrm{~g}\end{array}$ & - & - & - & - & $\begin{array}{l}3342.86 \pm 71.21 \\
\mathrm{mg} / 100 \mathrm{~g}\end{array}$ & $\begin{array}{l}\mathrm{NaOH} 2 \%(\mathrm{w} / \mathrm{v}) \\
20 \mathrm{~mL} \mathrm{NaOH} / \mathrm{g} \\
\text { Precipitation by ethanol } \\
30 \%(\mathrm{~V} / \mathrm{v})\end{array}$ & $120^{\circ} \mathrm{C}, 1.5 \mathrm{~h}$ & Ideia et al., 2020 \\
\hline
\end{tabular}




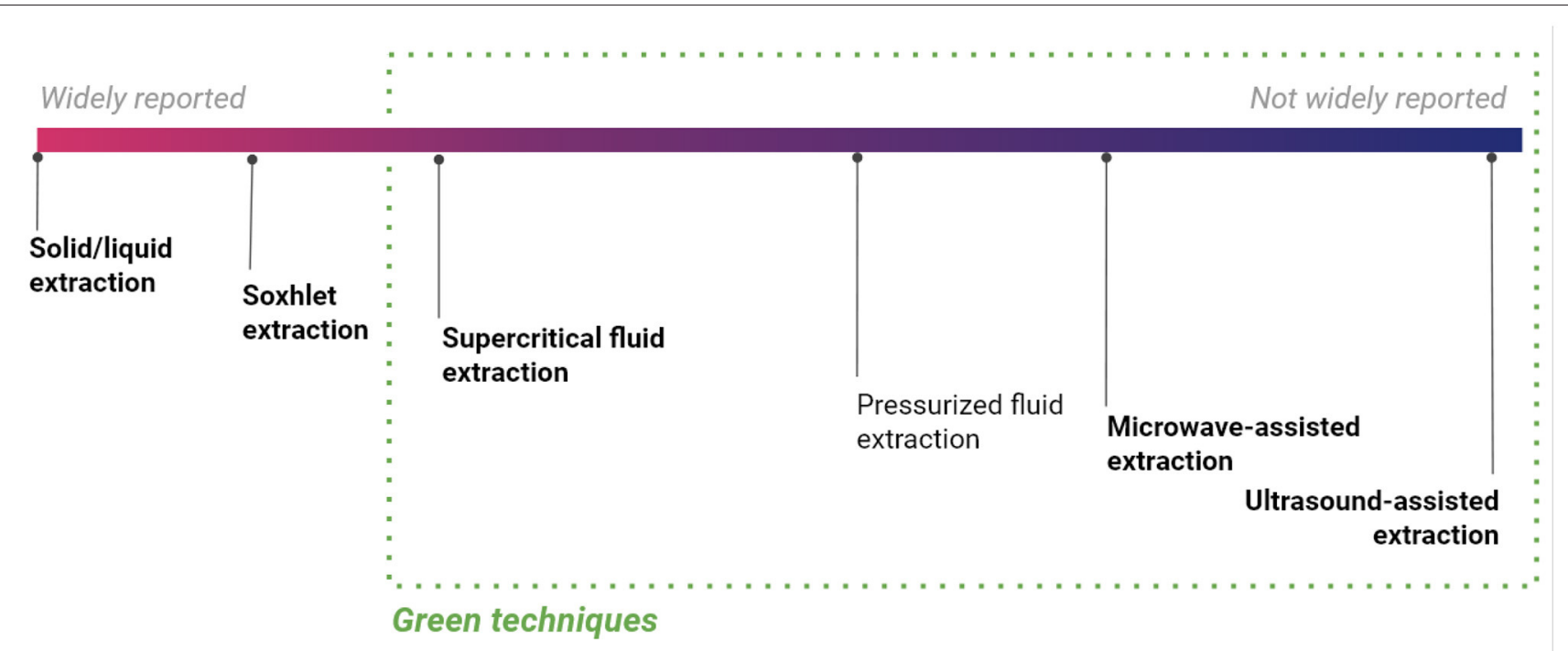

FIGURE 2 | Extractive methods reported for the extraction of phenolic compounds from BSG. Techniques in bold are discussed in the document.

time can be significantly reduced (Moreira et al., 2012). Rates of extraction are also enhanced due to the rise in temperature that the interaction of polar molecules and electromagnetic waves causes (Gil-Chávez et al., 2013). The efficiency of a MAE is dependent on the energy of the microwave, the time of treatment, and target temperature (Guido and Moreira, 2017). However, care must be taken as higher temperatures can produce the transformation of phenolic molecules into undesired compounds such as formic acid, levulinic acid, furfural, and degraded lignin (Tsubaki et al., 2010).

A work by Moreira et al. achieved the extraction of phenolic compounds under $15 \mathrm{~min}$, at $100^{\circ} \mathrm{C}$. A solution of $\mathrm{NaOH} 0.75 \%$ was used as a solvent. The yield for ferulic acid was $1.31 \pm 0.04 \%$ (w/w), a 5-times increase over the comparative SLE that the team prepared (Moreira et al., 2012). MAE offers reduced extraction times and solvent usage and is comparatively cheaper than SFE due to its simplicity; however, further separation steps to remove the solid matrix may be required during this procedure (Routray and Orsat, 2012; Guido and Moreira, 2017).

\section{Ultrasound-Assisted Extraction}

As MAE, ultrasound-assisted extraction (UAE) is an extractive technique with reduced use of solvents and higher extraction yields. The vibration of high-frequency sound waves $(>20 \mathrm{kHz})$ causes microcavities and bubbles in the solvent that collapse and create shear forces (cavitation) (Bonifácio-Lopes et al., 2019). The produced micro cavitation raises the temperature of the medium, breaking the cells' walls, and releasing their contents (Gil-Chávez et al., 2013).

Recently, Alonso-Riaño et al. (2020) realized an extensive valorization of the extractable compounds from BSG using UAE. This work reports a higher efficiency in total polyphenol extraction at $30 \mathrm{~min}$ of treatment using water as a solvent and pulses of $5 \mathrm{~s}$ of $20 \mathrm{kHz}$ waves at $47^{\circ} \mathrm{C}$. The total polyphenol content of obtained BSG extracts was determined using the FolinCiocalteu method, and a battery of phenolic compounds such as p-Coumaric acid, ferulic acid, sinapic acid among others, were characterized using HPLC-PAD. This ultrasound-assisted extraction approach produced a total yield of $0.118 \pm 0.004 \mathrm{mg}$ GAE/g dry BSG. Ferulic acid yields were reported at $10.7 \pm$ $0.3 \mu \mathrm{g} / \mathrm{g}$ dry BSG, and p-Coumaric acid was not detected. The obtained hydroxycinnamic acids were concentrated and purified from the protein fraction through centrifugal ultrafiltration with membranes of nominal molecular weight limit (NMWL) lower than $10 \mathrm{kDa}$.

\section{Autohydrolysis}

Hydrothermal pre-treatments are usually regarded as an environmentally friendly alternative compared to other chemical-based processes due to their dependence on only water and no other chemical as a reaction medium. In this group of processes, autohydrolysis has the objective of solubilizing interference hemicelluloses through the formation of acetic acid using acetyl groups of available hemicellulose by hydration oxygen ions of water. Resulting acetic acid molecules cause cleavage of hemicellulosic glycosidic bonds and reduce their degree of polymerization to enhance access to target extraction compounds.

A revalorization effort has been recently proposed by Wagner et al. (2021) for the revalorization of BSG through its autohydrolytic saccharification. When coupled with an enzymatic pretreatment, the acid autohydrolysis of BSG was validated as a mean to release carbohydrate products ( $5 \mathrm{~g}$ of sugar/gram dry of BSG) that may be fermented into value added compounds (e.g., xylitol, lactic acid, biofuels) to pose BSG as an integral biorefinery raw material. The release of polyphenols can be expected to occur as a coupled result of the saccharification of structural polymers 
of BSG, and thus this integral approximation can generate several products (Wagner et al., 2021).

\section{BSG PHENOLIC COMPOUNDS: APPLICATIONS FOR COSMETICS}

Phenolic compounds are potent antioxidants that have been studied and associated with the reduction and prevention of oxidative stress. The use of phenolic compounds extracted from BSG and applied to cosmetics has been proved to have skinlightening properties and have in vivo antioxidant properties (Almendinger et al., 2020). UV radiation is the primary source of oxidative stress in the skin; over-exposure may generate reactive oxygen species (ROS), causing extrinsic skin aging, damage, and permanent local hyperpigmentation or skin darkening (Almendinger et al., 2020). Additionally, the presence of these phenolic compounds have the added benefit of attenuating melanin synthesis by the inhibition of tyrosinase, the enzyme responsible for melanogenesis, the process of skin pigmentation, or discoloration (Almendinger et al., 2020). Tyrosinase is considered the rate-limiting enzyme for the catalytic oxidation of tyrosine to produce melanin. However, phytochemicals such as phenolic compounds share a similar molecular structure to this substrate because of their aromatic rings, making both of these compounds compete for the enzyme, therefore protecting the skin against melanogenesis. An additional benefit is that phenolic compounds could possess different pigments and aromatic compounds, making them more attractive and desired for the cosmetic industry.

During the beer-making process, barley is subject to a malting process involving high temperatures. Among the substances resulting from the barley malting process, the content of phenolic compounds has been consistently reported to vary during steeping, germination, and kilning. Additionally, the varying process conditions affect the composition and distribution of phenolic compounds found in BSG (see Table 3). This temperature rise also contributes to the onset of the Maillard reaction, a non-enzymatic type of browning, to occur on the malt. The resulting compounds of this reaction contribute to the sensory properties of the resulting beer and are thus of high relevance for brewers. The presence of melanoidins, a product of such reaction has to be considered when formulating an addedvalue product, especially when using non-purified phenolic compounds of BSG, as the excessive presence of antioxidants may have counterproductive reactions and cytotoxic effects (Liakos and Lazaridis, 2016; Panzella et al., 2020).

An in vitro study conducted by Almendinger et al. (2020) was made regarding the use of phenolic compounds obtained by aqueous extraction from BSG and applied to skincare products; the tyrosinase inhibition and antioxidant activity were determined for different phenolic concentrations ranging from 1 to $10 \%(\mathrm{v} / \mathrm{v})$ for cellular antioxidant activity and from 0.1 to $1 \%$ for tyrosinase inhibition activity. The total polyphenol content of obtained extracts was shown as higher on darker malts such as caramalt ( $12.9 \mathrm{mg} \mathrm{GAE} / \mathrm{g}$ extract), and lower values were obtained for spent grains $(1.8 \mathrm{mg} \mathrm{GAE} / \mathrm{g}$ of wheat beer spent grain). The results obtained from this study showed that there was a positive correlation between the number of phenolic compounds and antioxidant activity; additionally, the higher concentration of phenolic compounds, the higher was tyrosinases' inhibition rate (Almendinger et al., 2020). Additionally, higher antioxidant activity was shown on dark malt extracts, achieved through the synergic antioxidant action of polyphenol and melanoidins. This study showed promising results, but further studies need to be conducted explicitly regarding BSG extracted bioactive compounds applied to the cosmetic industry.

An additional study and economic analysis were conducted by Karlen et al. (2020) to test the viability of the extraction of hydroxycinnamic acids from lignocellulose-rich compounds. In this study, it was determined that the creation of a biorefinery precisely to extract hydroxycinnamic acids is not viable; commercially, FA and $\mathrm{p}-\mathrm{CA}$ are priced at around $\$ 1 / \mathrm{kg}$, but it will cost $\sim \$ 5.05 / \mathrm{kg}$ to extract them from these type of by-products. It was also explained that extracting each hydroxycinnamic acid, instead of them as a whole, would improve operational costs and yields; additionally, it was stated that extracting only these compounds will not be viable, a wide variety of extractions for different bioactive compounds need to be conducted simultaneously for a biorefinery to generate revenue. Complimentary use of residues can include polymers like cellulose, lignin, and pectin discussed elsewhere (Moreirinha et al., 2020) as valuable products since the policy transition for single-use plastics and complement the circular economy.

A general problem in extraction ventures is the recovery cost for phenolic compounds for their application in any industry. An exception to this hindrance is products of higher price, such as cosmetics. Cost barriers can be aided by the inclusion of cheaper extraction processes, as discussed in the previous section. One of these works was done by Zuorro et al. (2019), where the explored water-organic solvent method using ethanol and acetone resulted in yields of 50.9 and $70.6 \%$ at the same ratio of $60 \%$ organic solvent on water. In this case, the major phenolic compounds recovered were ferulic, p-coumaric, and caffeic acids (Zuorro et al., 2019). Moreover, the improvement of methodology can bring higher extraction yields, as presented by a recent work where the simplification of an alkaline high pressure extraction process increased the yield of FA by $38 \%$ compared to the previous method (Ideia et al., 2020).

Another relevant discussion for the use of phenolic compounds in cosmetic applications is the possibility of generating a proper formulation. In this regard, the formulations of five ferulic acid cocrystals for a topical product were generated and tested for several properties. The main two properties were stability and release of FA $0.5 \%(\mathrm{w} / \mathrm{w})$, inspired by the recent product wave from L'Oreal, e.g., CE FERULIC ${ }^{\circledR}$ and PHLORETIN $\mathrm{CF}^{\circledR}$ contain $0.5 \%$ of $\mathrm{FA}(\mathrm{w} / \mathrm{w})$, the best formulation was an oleogel $(99.19 \% \mathrm{w} / \mathrm{w})$ formulation containing ferulic acid-isonicotinamide $(0.81 \% \mathrm{w} / \mathrm{w})$ cocrystal (Aitipamula and Das, 2020). In order to generate the mentioned cocrystals, a critical characteristic of the isonicotinamide was its solubility; in this case, the use of any amphiphilic molecules such as hemicellulose can be directly incorporated into the 
TABLE 3 | Approximate concentration of most abundant phenolic compounds in BSG.

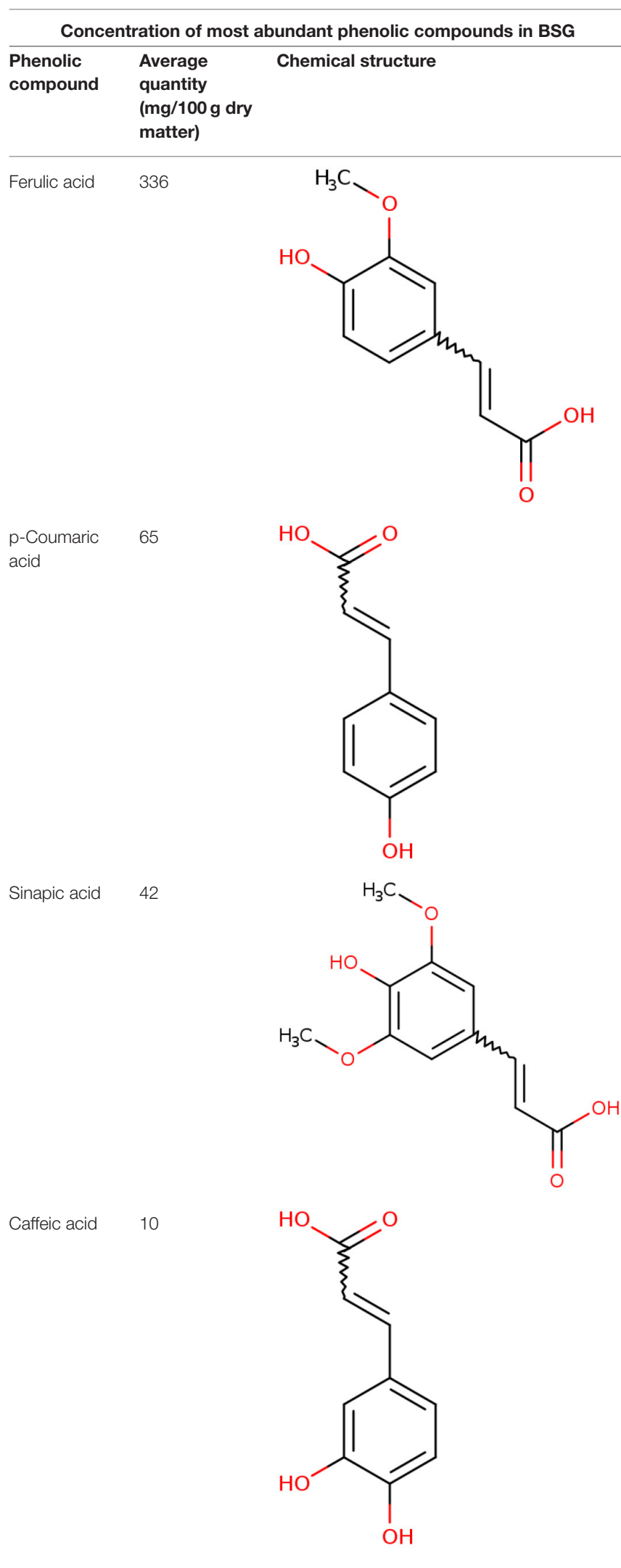

(Continued)
TABLE 3 | Continued

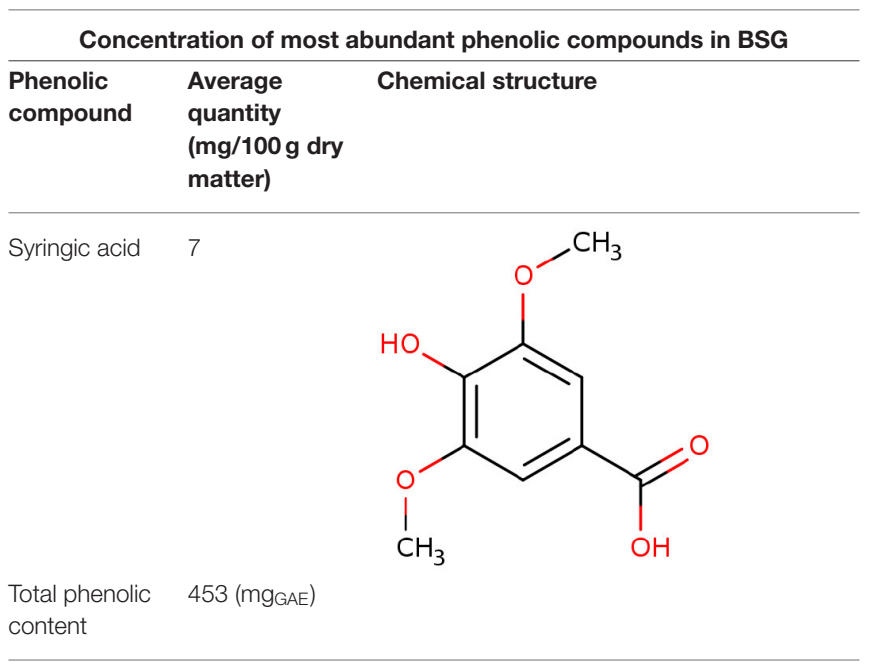

Adapted from Guido and Moreira (2017) and McCarthy et al. (2013). Marvin was used for drawing, chemical structures, Marvin 17.21.0, ChemAxon (https:// www.chemaxon.com).

cosmetic formulation. This implementation is an example where amphiphilic hemicellulose-based fatty micelles were synthesized with potential application in drug delivery, food, and cosmetics industries due to long-lasting stability (Shen et al., 2021). As mentioned in section Introduction, the main component of BSG is hemicellulose which accounts for $25 \%$ of its total weight and can also be incorporated into the formulation of cosmetic products as the amphiphilic stabilizer.

The application of these FA products is to help in the antioxidant and anti-aging activity, although FA stability against UV light is poor and the cocrystal tested in Aitipamula's work presented an excellent opportunity to develop a sunscreen with better stability (Aitipamula and Das, 2020). Another research done to evaluate antioxidant activity was explored with a sample of total phenolic compounds. The sample was added to linseed oil and was able to inhibit the oil's autoxidation reaction, showing an effect similar to $\alpha$-tocopherol (Ferrentino et al., 2019). The antioxidant properties of phenolic compounds found in BSG extracts were also highlighted by Connolly et al. (2021), along with their inhibitory capabilities for Dipeptidyl peptidase-IV (DPP-IV) and angiotensin-converting enzyme (ACE) as assessed in vivo in spontaneous hypertensive rats (SHR), a first for polyphenolic extracts from brewers spent grains. In this study, $50 \mathrm{mg}$ of BSG extract $/ \mathrm{kg}$ of body weight were administered and compared to a $10 \mathrm{mg}$ Captopril ${ }^{\mathrm{TM}} / \mathrm{kg}$ of body weight positive control, and a similar reduction in diastolic and systolic pressures and heart rate after $6 \mathrm{~h}$ of ingestion. The study concludes that albeit Captopril has a faster hypotensive effect, the used extracts had a prolonged action for up to $24 \mathrm{~h}$.

\section{PERSPECTIVES AND CHALLENGES}

The application of green extraction methods for the extraction of polyphenols of brewers' spent grains has proven its competitive 
advantage by reducing processing times, solvent usage, and energetic impact compared to conventional extraction strategies. Nevertheless, the implementation of emerging extraction technologies is hindered by cutting-edge equipment adapted to the exceptional processing conditions required. The use of specialized hardware also implies a higher upfront investment on technologies largely untested at an industrial scale, albeit once those processes are adapted to use one of the presented approaches, costs can be expected to be lowered due to the usage of cheaper solvents and lower requirements for waste management (Sridhar et al., 2021). This perspective opens the door to research in the pilot scale applications of the novel technologies in agroindustrial re-valorization.

The in vivo testing and commercial application of BSG polyphenol extracts also remains a challenge, as though their antioxidant potential has been widely reported and the mechanism of action understood, the viability of delivery of cosmeceutical compounds remains uncertain due to the poor stability, degradation, and oxidation of extracted phenols. The permeability of extracted natural antioxidants, such as those from BSG, in human skin strata has also not been thoroughly studied. For phenolic compounds, limited reports exist for species such as ferulic acid and p-Coumaric acid that reveal that for human models in conventional cosmetic formulations, phenolic skin permeability remains limited $\left(0.48 \pm 0.10 \mathrm{nmol} / \mathrm{cm}^{2}\right.$ of skin for ferulic acid), requiring the use of better delivery strategies such as permeation enhancers and compound nanoencapsulation (Casanova et al., 2016; Taofiq et al., 2017).

\section{CONCLUSIONS}

BSG is a cheap industrial by-product with wide availability that may be regarded as a low-cost and sustainable source of polyphenols as well as other bioactive molecules. Reviewed articles show that phenolic extracts from BSG exhibit good antioxidant properties at low concentrations and inhibit the tyrosinase activity of in vitro- keratinocyte cultures with low cytotoxicity (McCarthy et al., 2013; Almendinger et al., 2020; Verni et al., 2020). These features suggest that polyphenols extracted from BSG may be applied as skin-lightening agents for cosmeceutical products. However, further research is required to ensure the safety and reproducibility of these results by in vivo model tests.

A wide array of procedures for the recovery of phenolic compounds from BSG has already been explored. Traditional

\section{REFERENCES}

Aitipamula, S., and Das, S. (2020). Cocrystal formulations: a case study of topical formulations consisting of ferulic acid cocrystals. Europ. J. Pharm. Biopharm. 149, 95-104. doi: 10.1016/j.ejpb.2020.01.021

Aliyu, S., and Bala, M. (2011). Brewers Aliyu and Bala spent grain: a review of its potentials and applications. Af. J. Biotechnol. 10, 324-331. doi: $10.5897 / A J B 10.006$

Almendinger, M., Rohn, S., and Pleissner, D. (2020). Malt and beer-related byproducts as potential antioxidant skin-lightening agents for cosmetics. Susta. Chem. Pharm. 17:100282. doi: 10.1016/j.scp.2020.100282 techniques like solid/liquid extractions offer acceptable yields at low costs. However, the use of large quantities of solvent and long extraction times limit their application at high volumes of operation and raise environmental concerns. Novel methods for extraction labeled as "green techniques" offer improved yields at lower rates of reagent consumption and required time. This review cited SFE, MAE, and UAE as examples of sustainable approaches for the recovery of polyphenols from BSG; however, the research and optimization of such techniques are still not widely reported. Furthermore, the extraction rate may be improved using pre-treatments such as alkaline hydrolysis, autohydrolysis, or pulsed electric fields and have already been successfully applied to BSG phenolic extraction assays.

As with other lignocellulosic sources, the extraction of phenolic molecules is an excellent opportunity to offer additional revenue to biorefinery ventures that produce added-value compounds from BSG. The economic viability of such recovery must be considered, as the pre-treatment and purification steps may introduce technical challenges that might compromise the project's feasibility. BSG remains an underutilized source material of bioactive molecules. The use of its extracted phenolic compounds in cosmetics presents a novel opportunity to exploit this by-product and reduce generated waste by the circular economy approach presented in this revision.

\section{AUTHOR CONTRIBUTIONS}

RM-G conceived the original article idea, performed the main topic review, and wrote the original manuscript. SS-H contributed with literature review, table summarization, and manuscript writing. JS-H contributed with manuscript revision, ideas, and feedback throughout the manuscript development. RP-S sperformed manuscript revision and gave final approval for the manuscript to be submitted for publication. All authors contributed to the article and approved the submitted version.

\section{FUNDING}

This work was partially supported by the Consejo Nacional de Ciencia y Tecnología (CONACYT) and Tecnológico de Monterrey through the scholarship awarded to the first author (RM-G, CVU: 1013220), and co-author (SS-H, CVU: 1049103).
Alonso-Riaño, P., Sanz Diez, M. T., Blanco, B., Beltrán, S., Trigueros, E., and Benito-Román, O. (2020). Water ultrasound-assisted extraction of polyphenol compounds from brewer's spent grain: kinetic study, extract characterization, and concentration. Antioxidants 9:265. doi: 10.3390/antiox 9030265

Ameer, K., Shahbaz, H. M., and Kwon, J.-H. (2017). Green extraction methods for polyphenols from plant matrices and their byproducts: a review. Compre. Rev. Food Sci. Food Safety 16, 295-315. doi: 10.1111/1541-4337.12253

Birsan, R. I., Wilde, P., Waldron, K. W., and Rai, D. K. (2019). Recovery of polyphenols from Brewer's spent grains. Antioxidants 8, 380. doi: 10.3390/antiox8090380 
Bonifácio-Lopes, T., Teixeira, J. A., and Pintado, M. (2019). Current extraction techniques towards bioactive compounds from brewer's spent grain - a review. Crit. Rev. Food Sci. Nutr. 60, 2730-2741. doi: 10.1080/10408398.2019.1655632

Bouras, M., Grimi, N., Bals, O., and Vorobiev, E. (2016). Impact of pulsed electric fields on polyphenols extraction from Norway spruce bark. Indust. Crops Products 80, 50-58. doi: 10.1016/j.indcrop.2015.10.051

Bucci, P. L., Santos, M. V., Montanari, J., and Zaritzky, N. (2020). Nanoferulic: from a by-product of the beer industry toward the regeneration of the skin. J. Cosmetic Dermatol. 19, 2958-2964. doi: 10.1111/jocd.13407

Carciochi, R. A., Sologubik, C. A., Fernández, M. B., Manrique, G. D., and D'Alessandro, L. G. (2018). Extraction of antioxidant phenolic compounds from brewer's spent grain: optimization and kinetics modeling. Antioxidants 7:45. doi: 10.3390/antiox7040045

Casanova, F., Estevinho, B. N., and Santos, L. (2016). Preliminary studies of rosmarinic acid microencapsulation with chitosan and modified chitosan for topical delivery. Powder Technol. 297, 44-49. doi: 10.1016/j.powtec.2016.04.014

Connolly, A., Cermeño, M., Alashi, A. M., Aluko, R. E., and FitzGerald, R. J. (2021). Generation of phenolic-rich extracts from brewers' spent grain and characterisation of their in vitro and in vivo activities. Innovat. Food Sci. Emerg. Technol. 68:102617. doi: 10.1016/j.ifset.2021.102617

da Rosa Almeida, A., Geraldo, M. R. F., Ribeiro, L. F., Silva, M. V., Maciel, M. V., et al. (2017). Bioactive compounds from brewer's spent grain: Phenolic compounds, fatty acids and in vitro antioxidant capacity. Acta Scient. Technol. 39, 269-277. doi: 10.4025/actascitechnol.v39i3.28435

Di Domenico, M., Feola, A., Ambrosio, P., Pinto, F., Galasso, G., Zarrelli, A., et al. (2020). Antioxidant effect of beer polyphenols and their bioavailability in Dental-Derived Stem Cells (D-dSCs) and human intestinal epithelial lines (Caco-2) Cells. Stem Cells Int. 2020:e8835813. doi: 10.1155/2020/8835813

Ferrentino, G., Ndayishimiye, J., Haman, N., and Scampicchio, M. (2019). Functional activity of oils from Brewer's spent grain extracted by supercritical carbon dioxide. Food Bioprocess Technol. 12, 789-798. doi: 10.1007/s11947-019-02249-3

Fia, G., Bucalossi, G., Gori, C., Borghini, F., and Zanoni, B. (2020). Recovery of bioactive compounds from unripe red grapes (cv. Sangiovese) through a green extraction. Foods 9:566. doi: 10.3390/foods9050566

Fukagawa, S., Haramizu, S., Sasaoka, S., Yasuda, Y., Tsujimura, H., and Murase, T. (2017). Coffee polyphenols extracted from green coffee beans improve skin properties and microcirculatory function. Biosci. Biotechnol. Biochem. 81, 1814-1822. doi: 10.1080/09168451.2017.1345614

Gil-Chávez, G. J., Villa, J. A., Ayala-Zavala, J. F., Heredia, J. B., Sepulveda, D., Yahia, E. M., et al. (2013). Technologies for extraction and production of bioactive compounds to be used as nutraceuticals and food ingredients: an overview. Compre. Rev. Food Sci. Food Safety 12, 5-23. doi: 10.1111/1541-4337. 12005

Guido, L. F., and Moreira, M. M. (2017). Techniques for extraction of Brewer's spent grain polyphenols: a review. Food Bioprocess Technol. 10, 1192-1209. doi: 10.1007/s11947-017-1913-4

Hernanz, D., Nuñez, V., Sancho, A. I., Faulds, C. B., Williamson, G., Bartolomé, B., et al. (2001). Hydroxycinnamic acids and ferulic acid dehydrodimers in barley and processed barley. J. Agric. Food Chem. 49, 4884-4888. doi: $10.1021 /$ jf010530u

Herrero, M., Mendiola, J. A., Cifuentes, A., and Ibáñez, E. (2010). Supercritical fluid extraction: recent advances and applications. J. Chromatography A 1217, 2495-2511. doi: 10.1016/j.chroma.2009.12.019

Ideia, P., Sousa-Ferreira, I., and Castilho, P. C. (2020). A novel and simpler alkaline hydrolysis methodology for extraction of ferulic acid from Brewer's spent grain and its (Partial) purification through adsorption in a synthetic resin. Foods 9:600. doi: 10.3390/foods9050600

Ikram, S., Zhang, H., Ming, H., and Wang, J. (2020). Recovery of major phenolic acids and antioxidant activity of highland barley brewer's spent grains extracts. J. Food Process. Preserv. 44:e14308. doi: 10.1111/jfpp. 14308

Karlen, S. D., Fasahati, P., Mazaheri, M., Serate, J., Smith, R. A., Sirobhushanam, S., et al. (2020). Assessing the viability of recovery of hydroxycinnamic acids from lignocellulosic biorefinery alkaline pretreatment waste streams. ChemSusChem 13, 2012-2024. doi: 10.1002/cssc.201903345

Kitryte, V., Šaduikis, A., and Venskutonis, P. R. (2015). Assessment of antioxidant capacity of brewer's spent grain and its supercritical carbon dioxide extract as sources of valuable dietary ingredients. J. Food Eng. 167, 18-24. doi: 10.1016/j.jfoodeng.2014.12.005

Kumari, B., Tiwari, B. K., Walsh, D., Griffin, T. P., Islam, N., Lyng, J. G., et al. (2019). Impact of pulsed electric field pre-treatment on nutritional and polyphenolic contents and bioactivities of light and dark brewer's spent grains. Innovat. Food Sci. Emerg. Technol. 54, 200-210. doi: 10.1016/j.ifset.2019.04.012

Leal, C., Gouvinhas, I., Santos, R. A., Rosa, E., Silva, A. M., Saavedra, M. J., et al. (2020). Potential application of grape (Vitis vinifera L.) stem extracts in the cosmetic and pharmaceutical industries: valorization of a by-product. Indust. Crops Products 154:112675. doi: 10.1016/j.indcrop.2020.112675

Liakos, T. I., and Lazaridis, N. K. (2016). Melanoidin removal from molasses effluents by adsorption. J. Water Process Eng. 10, 156-164. doi: 10.1016/j.jwpe.2016.02.006

López-Linares, J. C., Campillo, V., Coca, M., Lucas, S., and García-Cubero, M. T. (2021). Microwave-assisted deep eutectic solvent extraction of phenolic compounds from brewer's spent grain. J. Chem. Technol. Biotechnol. 96, 481-490. doi: 10.1002/jctb.6565

Lynch, K. M., Steffen, E. J., and Arendt, E. K. (2016). Brewers' spent grain: a review with an emphasis on food and health. J. Inst. Brewing 122, 553-568. doi: $10.1002 /$ jib.363

McCarthy, A. L., O'Callaghan, Y. C., Connolly, A., Piggott, C. O., FitzGerald, R. J., and O'Brien, N. M. (2013). In vitro antioxidant and anti-inflammatory effects of brewers' spent grain protein rich isolate and its associated hydrolysates. Food Res. Int. 50, 205-212. doi: 10.1016/j.foodres.2012.10.022

Meneses, N. G. T., Martins, S., Teixeira, J. A., and Mussatto, S. I. (2013). Influence of extraction solvents on the recovery of antioxidant phenolic compounds from brewer's spent grains. Sep. Purific. Technol. 108, 152-158. doi: 10.1016/j.seppur.2013.02.015

Moreira, M. M., Morais, S., Barros, A. A., Delerue-Matos, C., and Guido, L. F. (2012). A novel application of microwave-assisted extraction of polyphenols from brewer's spent grain with HPLC-DAD-MS analysis. Anal. Bioanal. Chem. 403, 1019-1029. doi: 10.1007/s00216-011-5703-y

Moreirinha, C., Vilela, C., Silva, N. H. C. S., Pinto, R. J. B., Almeida, A., Rocha, M. A. M., et al. (2020). Antioxidant and antimicrobial films based on brewers spent grain arabinoxylans, nanocellulose and feruloylated compounds for active packaging. Food Hydrocolloids 108:105836. doi: 10.1016/j.foodhyd.2020.105836

Mussatto, S. I., Fernandes, M., Milagres, A. M. F., and Roberto, I. C. (2008). Effect of hemicellulose and lignin on enzymatic hydrolysis of cellulose from brewer's spent grain. Enzyme Microb. Technol. 43, 124-129. doi: 10.1016/j.enzmictec.2007.11.006

Niemi, P., Faulds, C. B., Sibakov, J., Holopainen, U., Poutanen, K., and Buchert, J. (2012). Effect of a milling pre-treatment on the enzymatic hydrolysis of carbohydrates in brewer's spent grain. Bioresour. Technol. 116, 155-160. doi: 10.1016/j.biortech.2012.04.043

Panzella, L., Moccia, F., Nasti, R., Marzorati, S., Verotta, L., and Napolitano, A. (2020). Bioactive phenolic compounds from agri-food wastes: an update on green and sustainable extraction methodologies. Front. Nutrit. 7:60. doi: 10.3389/fnut.2020.00060

Patrignani, M., and González-Forte, L. S. (2021). Characterisation of melanoidins derived from Brewers' spent grain: new insights into their structure and antioxidant activity. Int. J. Food Sci. Technol. 56, 384-391. doi: 10.1111/ijfs.14653

Petrón, M. J., Andrés, A. I., Esteban, G., and Timón, M. L. (2021). Study of antioxidant activity and phenolic compounds of extracts obtained from different craft beer by-products. J. Cereal Sci. 98:103162. doi: 10.1016/j.jcs.2021.103162

Pinheiro, T., Coelho, E., Romaní, A., and Domingues, L. (2019). Intensifying ethanol production from brewer's spent grain waste: use of whole slurry at high solid loadings. N. Biotechnol. 53, 1-8. doi: 10.1016/j.nbt.2019.06.005

Routray, W., and Orsat, V. (2012). Microwave-assisted extraction of flavonoids: a review. Food Bioprocess Technol. 5, 409-424. doi: 10.1007/s11947-011-0573-z

Santos, M., Jiménez, J. J., Bartolomé, B., Gómez-Cordovés, C., and del Nozal, M. J. (2003). Variability of brewer's spent grain within a brewery. Food Chem. 80, 17-21. doi: 10.1016/S0308-8146(02)00229-7

Shen, R., Wang, H., Wu, K., Gao, J., and Li, J. (2021). Characterization and antimicrobial properties of ferulic acid grafted self-assembled bacterial cellulose-chitosan membranes. J. Appl. Polymer Sci. 50824. doi: 10.1002/app.50824 
Sibhatu, H. K., Anuradha Jabasingh, S., Yimam, A., and Ahmed, S. (2021). Ferulic acid production from brewery spent grains, an agro-industrial waste. LWT 135:110009. doi: 10.1016/j.lwt.2020.110009

Socaci, S. A., Fărca,ş, A. C., Diaconeasa, Z. M., Vodnar, D. C., Rusu, B., and Tofan, $\breve{a}$, M. (2018). Influence of the extraction solvent on phenolic content, antioxidant, antimicrobial and antimutagenic activities of brewers' spent grain. J. Cereal Sci. 80, 180-187. doi: 10.1016/j.jcs.2018.03.006

Sosa-Hernández, J. E., Escobedo-Avellaneda, Z., Iqbal, H., and Welti-Chanes, J. (2018). State-of-the-art extraction methodologies for bioactive compounds from algal biome to meet bio-economy challenges and opportunities. Molecules 23:2953. doi: 10.3390/molecules23112953

Spinelli, S., Conte, A., Lecce, L., Padalino, L., and Del Nobile, M. A. (2016). Supercritical carbon dioxide extraction of brewer's spent grain. J. Supercritic. Fluids 107, 69-74. doi: 10.1016/j.supflu.2015.08.017

Sridhar, A., Ponnuchamy, M., Kumar, P. S., Kapoor, A., Vo, D.-V. N., and Prabhakar, S. (2021). Techniques and modeling of polyphenol extraction from food: a review. Environ. Chem. Lett. 1-35. doi: 10.1007/s10311-021-01217-8

Stalikas, C. D. (2007). Extraction, separation, and detection methods for phenolic acids and flavonoids. J. Sep. Sci. 30, 3268-3295. doi: 10.1002/jssc.200700261

Taofiq, O., González-Paramás, A. M., Barreiro, M. F., and Ferreira, I. C. F. R. (2017). Hydroxycinnamic acids and their derivatives: cosmeceutical significance, challenges and future perspectives, a review. Molecules 22:281. doi: 10.3390/molecules22020281

Tsubaki, S., Sakamoto, M., and Azuma, J. (2010). Microwave-assisted extraction of phenolic compounds from tea residues under autohydrolytic conditions. Food Chem. 123, 1255-1258. doi: 10.1016/j.foodchem.2010. 05.088

Vellingiri, V., Amendola, D., and Spigno, G. (2014). Screening of four different agro-food by-products for the recovery of antioxidants and cellulose. Chem. Eng. Trans. 37, 757-762. doi: 10.3303/CET1437127

Vernès, L., Vian, M., and Chemat, F. (2020). "Chapter 12-ultrasound and microwave as green tools for solid-liquid extraction," in
Liquid-Phase Extraction, ed C. F. Poole (Elsevier), 355-374. doi: 10.1016/B978-0-12-816911-7.00012-8

Verni, M., Pontonio, E., Krona, A., Jacob, S., Pinto, D., Rinaldi, F., et al. (2020). Bioprocessing of Brewers' spent grain enhances its antioxidant activity: characterization of phenolic compounds and bioactive peptides. Front. Microbiol. 11:1831. doi: 10.3389/fmicb.2020.01831

Wagner, E., Pería, M. E., Ortiz, G. E., Rojas, N. L., and Ghiringhelli, P. D. (2021). Valorization of brewer's spent grain by different strategies of structural destabilization and enzymatic saccharification. Indust. Crops Products 163:113329. doi: 10.1016/j.indcrop.2021.113329

Wang, L., and Weller, C. L. (2006). Recent advances in extraction of nutraceuticals from plants. Trends Food Sci. Technol. 17, 300-312. doi: 10.1016/j.tifs.2005.12.004

Wilkinson, S., Smart, K. A., and Cook, D. J. (2014). Optimisation of alkaline reagent based chemical pre-treatment of Brewers spent grains for bioethanol production. Indust. Crops Products 62, 219-227. doi: 10.1016/j.indcrop.2014.08.036

Zuorro, A., Iannone, A., and Lavecchia, R. (2019). Water-organic solvent extraction of phenolic antioxidants from Brewers' spent grain. Processes 7:126. doi: $10.3390 /$ pr7030126

Conflict of Interest: The authors declare that the research was conducted in the absence of any commercial or financial relationships that could be construed as a potential conflict of interest.

Copyright (C) 2021 Macias-Garbett, Serna-Hernández, Sosa-Hernández and ParraSaldivar. This is an open-access article distributed under the terms of the Creative Commons Attribution License (CC BY). The use, distribution or reproduction in other forums is permitted, provided the original author(s) and the copyright owner(s) are credited and that the original publication in this journal is cited, in accordance with accepted academic practice. No use, distribution or reproduction is permitted which does not comply with these terms. 